\title{
Children at high altitude have less nocturnal periodic breathing than adults
}

\author{
M. Kohler*, S. Kriemler", E.M. Wilhelm*, H. Brunner-LaRocca ${ }^{\star}$, \\ M. Zehnder ${ }^{+}$and K.E. Bloch ${ }^{\star}, \S$
}

ABSTRACT: Although children commonly travel to high altitudes, their respiratory adaptation to hypoxia remains elusive. Therefore, in the present study respiratory inductive plethysmography, pulse oximetry $\left(\mathrm{Sp}, \mathrm{O}_{2}\right)$ and end-tidal $\mathrm{CO}_{2}$ tension $\left(\mathrm{PET}, \mathrm{CO}_{2}\right)$ were recorded in 20 pre-pubertal children (aged 9-12 yrs) and their fathers during 1 night in Zurich (490 m) and 2 nights at the Swiss Jungfrau-Joch research station $(3,450 \mathrm{~m})$ following ascent by train within $<\mathbf{3} \mathbf{h}$.

In children, mean \pm SD nocturnal $\mathrm{Sp}, \mathrm{O}_{2}$ fell from $98 \pm 1 \%$ at $490 \mathrm{~m}$ to $85 \pm 4$ and $86 \pm 4 \%$ at $3,450 \mathrm{~m}$ (nights 1 and 2, respectively); $P E T, \mathrm{CO}_{2}$ decreased significantly from $37 \pm 6$ to $32 \pm 3$ and $33 \pm 4 \mathrm{mmHg}(3,450$ versus $490 \mathrm{~m})$. In adults, changes in nocturnal $\mathrm{Sp}, \mathrm{O}_{2}$ and $P \mathrm{ET}, \mathrm{CO}_{2}$ at $3,450 \mathrm{~m}$ were similar to those in children.

Children spent less time in periodic breathing at 3,450 m during night 1 and 2 (8 \pm 11 and $9 \pm 13 \%$, respectively) than adults ( $34 \pm 24$ and $22 \pm 17 \%$, respectively), and their apnoea threshold for $\mathrm{CO}_{2}$ was lower compared with adults $(27 \pm 2$ and $30 \pm 2 \mathrm{mmHg}$, respectively, both nights). $\mathrm{Sp}, \mathrm{O}_{2}, \mathrm{PET}, \mathrm{CO}_{2}$ and time in periodic breathing at altitude were not correlated between children and their fathers.

In conclusion, children revealed a similarly reduced nocturnal $\mathrm{O}_{2}$ saturation and associated hyperventilation at high altitude as adults but their breathing pattern was more stable, possibly related to a lower apnoea threshold for $\mathrm{CO}_{2}$.

KEYWORDS: Acute mountain sickness, apnoea, high altitude, hypoxia, periodic breathing

M any families with children travel to high mountain areas for leisure activities, to pursue a parental occupation and for other reasons [1]. However, little is known about children's respiratory adaptation to hypobaric hypoxia and their tolerance of high altitude. In adults, hypobaric hypoxia increases ventilation and induces respiratory alkalosis [2-4]. This attenuates hypoxaemia but may also destabilise ventilation due to hypocapnia that triggers apnoea [5]. Periodic breathing characterised by crescendodecrescendo ventilation with hyperpnoea alternating with hypopnoea/apnoea is typically observed in adults at high altitude. Periodic breathing causes frequent arousals from sleep [6,7] resulting in poor sleep quality, one of the manifestations of acute mountain sickness $[8,9]$. There is a considerable inter-subject variability in periodic breathing due to individual differences in autonomic control of ventilation [10]. According to feedback control theory, susceptibility to periodic breathing depends on various factors, such as on controller gain, gas exchange, the circulation time and response lags involved in the chemoreflex feedback [11] Consistent with this theory, periodic breathing has been induced in animals by inserting a circulatory delay system between the lungs and the brain [12] or by augmenting controller gain by an increase in the gain of a servo-respirator during mechanical ventilation [13]. Furthermore, ventilatory instability and periodic breathing have been shown to depend on the proximity of the eupnoeic carbon dioxide tension $\left(\mathrm{PCO}_{2}\right)$ to the apnoeic and hypopnoeic threshold $\mathrm{PCO}_{2}$, as well as on the ventilatory sensitivity to $\mathrm{CO}_{2}$ below eupnoea [14] . These factors may differ between children and adults and may affect ventilation, oxygenation and thereby well-being and performance at high altitude [15-17]. As respiratory adaptation to acute altitude exposure has not been studied in detail in children, the current authors performed unobtrusive breathing pattern recordings by calibrated respiratory inductive plethysmography and actimetry in pre-pubertal children and their fathers.

Earn CME accreditation by answering questions about this article. You will find these at the back of the printed copy of this issue or online at www.erj.ersjournals.com/current.shtml

AFFILIATIONS

*Pulmonary Division, Dept of Internal Medicine, University Hospital of Zurich,

${ }^{\S}$ Zurich Center for Integrative Human Physiology,

${ }^{+}$Institute of Exercise Physiology, University of Zurich, Zurich,

${ }^{*}$ Institute of Sport and Health

Sciences, and

'Division of Cardiology, University Hospital of Basel, Basel, Switzerland.

CORRESPONDENCE

K.E. Bloch

Pulmonary Division

Dept of Internal Medicine

University Hospital of Zurich

Ramistrasse 100

$\mathrm{CH}-8091$ Zurich

Switzerland

Fax: 41442554451

E-mail: konrad.bloch@usz.ch

Received:

September 102007

Accepted after revision:

February 042008

STATEMENT OF INTERES

None declared. 
Studies were performed at low altitude in Zurich $(490 \mathrm{~m})$ and during 2 consecutive nights at the Jungfrau-Joch high-altitude research station $(3,450 \mathrm{~m})$, Switzerland. Some of the results of these studies have been reported previously as a case report [18].

\section{METHODS}

\section{Subjects}

In total, 20 pre-pubertal children (four young females) at Tanner stage I $[19,20]$, i.e. without clinical signs of puberty, aged mean \pm SD (range) $11 \pm 1(9-12)$ yrs, and with a body mass index of (BMI) $16.2 \pm 2.0 \mathrm{~kg} \cdot \mathrm{m}^{-2}$, were recruited from lowland residencies $(<1,000 \mathrm{~m})$ in Switzerland. In addition, 20 males (19 were biological fathers of participating children) aged $44 \pm 4(36-57) \mathrm{yrs}$, and with a BMI of $23 \pm 1.6 \mathrm{~kg} \cdot \mathrm{m}^{-2}$ were recruited from lowland residencies $(<1,000 \mathrm{~m})$ in Switzerland. Participants were healthy, did not suffer from any sleep or breathing disorder, and had not stayed at altitudes $>2,000 \mathrm{~m}$ in the 2 months prior to the study. No drugs other than paracetamol were allowed to treat high altitude-related headaches. All participants gave informed consent and the Institutional Ethics Committee of the University of Zurich (Zurich, Switzerland) approved the study.

\section{Measurements}

A medical history and physical examination were obtained. Acute mountain sickness (AMS) was assessed using the environmental symptoms questionnaire (ESQ); a cerebral score with $\geqslant 0.7$ points was considered to indicate AMS [21]. Participants were assisted in filling out the questionnaires by an investigator.

Nocturnal polygraphic studies included: calibrated respiratory inductive plethysmography (SomnostarPT; Sensormedics, Yorba Linda, CA, USA), pulse oximetry, ECG, and capnography of expired air to estimate end-tidal $\mathrm{CO}_{2}$ tension $\left(P \mathrm{ET}, \mathrm{CO}_{2}\right)$ as a surrogate of arterial $\mathrm{PCO}_{2}\left(\mathrm{~Pa}_{2} \mathrm{CO}_{2}\right.$; CapnoSleep; Weinmann, Hamburg, Germany). The technical pulse oximeter response time from sensor disconnection to a drop in $\mathrm{O}_{2}$ saturation was $8.5 \mathrm{~s}$. The capnograph response time from the beginning of the rise in $\mathrm{CO}_{2}$ concentration to $90 \%$ of maximal amplitude after switching from room air to a $5 \% \mathrm{CO}_{2}$ mixture was $0.6 \mathrm{~s}$. The respiratory inductive plethysmograph was first calibrated using the Qualitative Diagnostic Calibration method [22], and then against the integrated output of a flow meter during 10-20 breaths [23]. Validation of the calibration in the morning after sleep studies revealed a deviation of tidal volume $(V T)$ by inductance plethysmography from corresponding flow meter values of $\leqslant 20 \%$ in all instances. Wrist actigraphy was performed as an indirect measure of sleep and wakefulness (Actiwatch; Cambridge Neurotechnology, Cambridge, UK) [8, 24].

\section{Protocol}

Father and child pairs underwent baseline examinations in Zurich $(490 \mathrm{~m})$. They ascended to the Jungfrau-Joch research station $(3,450 \mathrm{~m})$ 2-4 weeks later by a $<3$-h train ride and stayed there for $48 \mathrm{~h}$. Nocturnal polygraphic recordings were performed during 1 night at $490 \mathrm{~m}$ and during the 2 nights at 3,450 $\mathrm{m}$. The nocturnal rest period lasted $\sim 8 \mathrm{~h}$, from 22:0006:00. Clinical examination and assessment of AMS were performed in the evenings and mornings.

\section{Data analysis and statistics}

Polygraphic recordings were analysed from lights off in the evening to lights on in the morning. This period was defined as time in bed (TIB). Breathing pattern variables derived from respiratory inductive plethysmography were measured breath-by-breath and mean values were computed for TIB [23]. Periodic breathing was defined as a pattern of waxing and waning of ventilation with periods of hyperventilation alternating with central apnoeas/hypopnoeas for at least three successive cycles, with hypopnoeas showing a $>50 \%$ amplitude reduction of the inductive plethysmographic $V \mathrm{~T}$ signal compared with the preceding 2-min baseline of stable breathing for $>5 \mathrm{~s}$ (fig. 1) $[5,8,25]$. The number of periodic breathing cycles, their length (the cycle time), and the fraction of TIB spent with periodic breathing were determined. Occasional apnoeas/hypopnoeas that were not part of periodic breathing were defined as a reduction of the inductive plethysmographic $V$ T signal to $<50 \%$ of the preceding 2 min baseline of stable breathing during $\geqslant 10 \mathrm{~s}$ in adults and during $\geqslant 5 \mathrm{~s}$ in children $[26,27]$. Obstructive apnoeas/hypopnoeas were differentiated from central events by ribcage-abdominal asynchrony [23] and by continued chest wall excursions in the absence of $\mathrm{PET}, \mathrm{CO}_{2}$ deflections. The apnoea/hypopnoea index (AHI) was defined as the number of apnoeas/hypopnoeas (including periodic breathing cycles) per hour TIB. $\mathrm{O}_{2}$ desaturations $\geqslant 4 \%$ per hour of TIB were determined as the $\mathrm{O}_{2}$ desaturation index. Sighs were defined as large breaths with $V$ Ts greater than twice the previous stable $V \mathrm{~T}$ amplitude [28]. The $\mathrm{CO}_{2}$ apnoea threshold was defined as the value of $P \mathrm{ET}, \mathrm{CO}_{2}$ of the last breath before an apnoea occurred [29]. The $\mathrm{CO}_{2}$ reserve $\left(\Delta P \mathrm{ET}, \mathrm{CO}_{2}\right)$ was calculated as the difference in $P \mathrm{ET}, \mathrm{CO}_{2}$ during eupnoea and the $\mathrm{CO}_{2}$ apnoea threshold. The lung-to-finger circulation time was measured as the time from the end of an apnoea to the subsequent nadir of arterial $\mathrm{O}_{2}$ saturation as an estimate of the circulatory delay from the lungs to the peripheral chemoreceptors [29]. To evaluate whether there were differences in circulation time between children and adults independent of body size, the circulation time was also expressed as time in seconds divided by height. Oximeter probes were placed on the finger rather than on the ear lobe as this was found to be less disturbing to the children. Mean $\mathrm{CO}_{2}$ apnoea threshold and circulation time from three consecutive apnoea/hyperpnoea cycles were measured every $15 \mathrm{~min}$ if applicable. Activity and rest periods were derived from actigraphy with dedicated software. The acceleration level below which sleep is assumed was graphically assigned [24]. Time with acceleration below threshold was defined as rest time, and estimated sleep efficiency as rest time in per cent of TIB.

Results are expressed as mean $\pm \mathrm{SD}$. Measurements at different altitudes and between children and fathers were compared by ANOVA followed by Newman-Keuls tests if appropriate. A probability of $\mathrm{p}<0.05$ was assumed to be significant.

\section{RESULTS}

In total, 17 children and 19 of the adults completed the entire protocol. One child returned home with his father after the first night at $3,450 \mathrm{~m}$ because of homesickness; one child was withdrawn from the study as she developed severe AMS [18]; and in one child, the cardiorespiratory sleep study on the 
a)
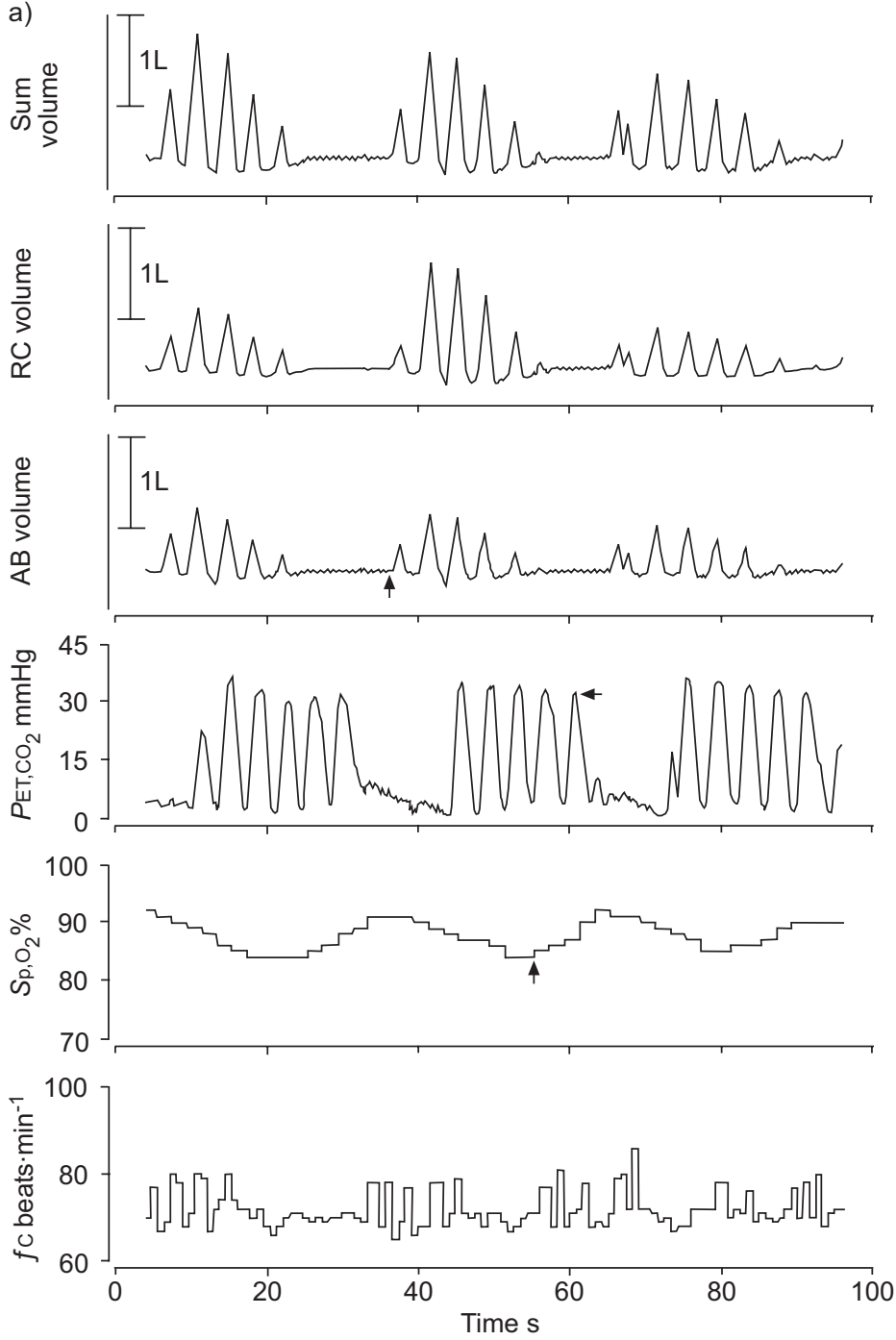
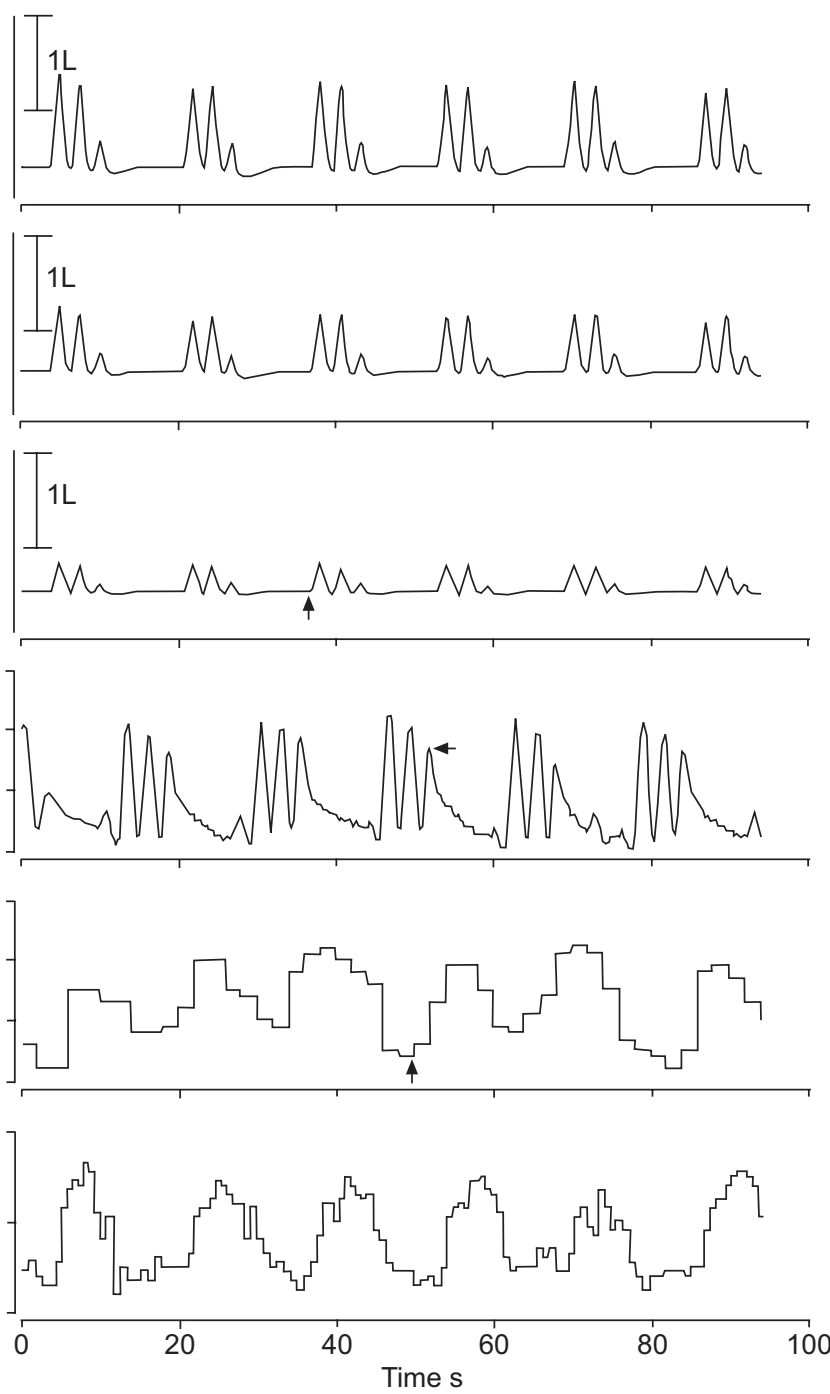

FIGURE 1. Nocturnal polygraphic recording obtained at 3,450 $\mathrm{m}$ in a) a 43-yr-old father and b) his 11-yr-old son. Inductive plethysmographic signals reflecting the volume of the ribcage $(\mathrm{RC})$, the abdomen $(\mathrm{AB})$ and their sum, the lung volume. The end-tidal carbon dioxide tension $\left(P \mathrm{ET}, \mathrm{CO}_{2}\right)$, arterial oxygen saturation measured by pulse oximetry $\left(\mathrm{Sp}, \mathrm{O}_{2}\right)$ and cardiac frequency $(\mathrm{fc})$ measured by ECG are also shown. There is a periodic breathing pattern associated with fluctuations in $\mathrm{Sp}, \mathrm{O}_{2}$ and $f_{\mathrm{c}}$. This was extraordinarily pronounced in this child. The apnoea threshold for carbon dioxide is lower in the boy ( $b ; 25 \mathrm{mmHg}$, horizontal arrow) than in his father (a; $30 \mathrm{mmHg}$, horizontal arrow). The circulation time measured as the time from the end of an apnoea to the corresponding nadir in arterial oxygen saturation (vertical arrows) is shorter in the boy (b; $12 \mathrm{~s}$, ) than for the father $(\mathrm{a} ; 19 \mathrm{~s})$.

second night at 3,450 $\mathrm{m}$ could not be analysed because of technical failure.

Results of polygraphic studies are summarised in table 1. In children and adults mean nocturnal $\mathrm{O}_{2}$ saturation was significantly reduced by $11 \%$ to $13 \%$ during the first and second night at 3,450 $\mathrm{m}$ when compared to baseline at $490 \mathrm{~m}$. This was associated with a significant increase in minute ventilation $\left(V^{\prime} \mathrm{E}\right)$ that was similar in children and adults when expressed in per cent of the corresponding baseline value at $490 \mathrm{~m}$, although absolute values in $\mathrm{L} \cdot \mathrm{min}^{-1}$ were higher in adults. Consistent with an increased respiratory centre drive that induced hyperventilation, mean inspiratory flow ( $V \mathrm{~T} /$ inspiratory time) at 3,450 $\mathrm{m}$ was increased by $22 \%$ to $45 \%$ above baseline values at $490 \mathrm{~m}$, while $P$ ET, $\mathrm{CO}_{2}$ was decreased. These changes were similar in children and adults (table 1). Children achieved their increased $V^{\prime} \mathrm{E}$ mainly by increasing the breath rate, whereas adults increased both the breath rate and the $V$ T. Compared with adults, cardiac frequency $(f C)$ in children was already higher at baseline and increased even more at high altitude. Actigraphical recordings revealed that rest time and estimated sleep efficiency decreased significantly in the first night at high altitude in children and adults (table 1 ).

The analysis of transient respiratory events is summarised in table 2. In children and adults the observed apnoeas and hypopnoeas were nearly exclusively of the central type ( $>99 \%)$ and occurred as part of a periodic breathing pattern. Therefore, central and obstructive apnoeas/hypopnoeas are not reported separately. At $490 \mathrm{~m}$, apnoeas/hypopnoeas were rarely detected. In contrast, at $3,450 \mathrm{~m}$, periodic breathing with central apnoeas/hypopnoeas was common in children and 
TABLE 1 Nocturnal polygraphic recordings

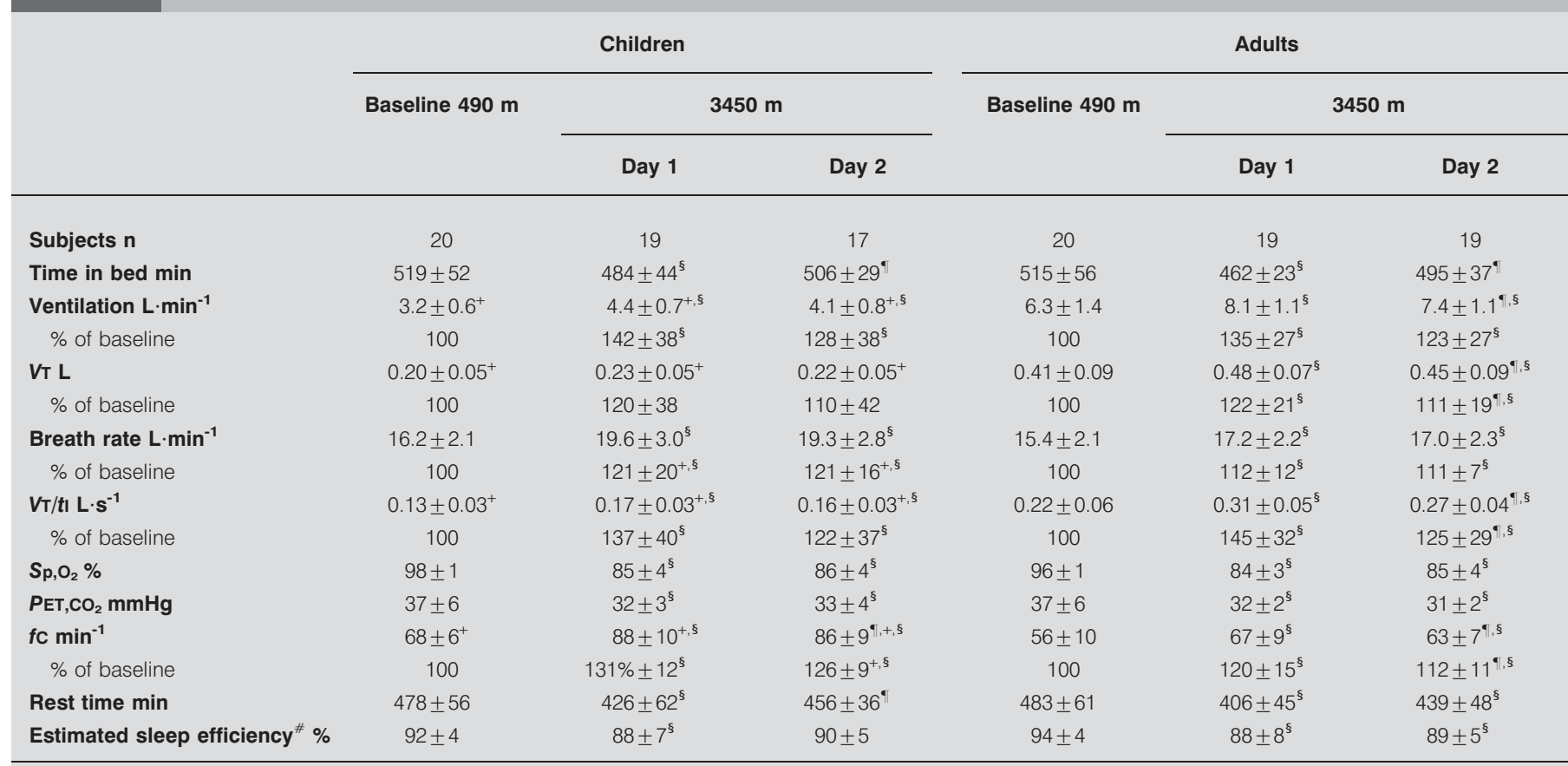

Data are presented as mean $\pm \mathrm{SD}$, unless otherwise stated. $V \mathrm{~T}$ : tidal volume; $t \mathrm{l}$ : inspiratory time; $\mathrm{Sp}_{2} \mathrm{O}_{2}: \mathrm{O}_{2}$ saturation measured by pulse oximetry; $P \mathrm{ET}, \mathrm{CO}_{2}:$ end-tidal $\mathrm{CO}_{2}$ tension; fC: cardiac frequency. ${ }^{*}$ : rest time measured by actigraphy in per cent of time in bed; ${ }^{\circ}: p<0.05$ versus day $1 ;^{+}: p<0.05$ versus adults; ${ }^{\S}: p<0.05$ versus $460 \mathrm{~m}$.

adults. However, children had less apnoea/hypopnoea at 3,450 m. During the first night they spent less than a quarter of the time with periodic breathing compared with adults (table 2, fig. 2). On the second night at 3,450 m, adults had a slight reduction in the AHI compared with the first night but their AHI was still higher than that of children who spent less than half of the time in periodic breathing compared with adults. Children had less cyclical $\mathrm{O}_{2}$ desaturations than adults, but their swings in $\mathrm{O}_{2}$ saturation tended to be more pronounced than in adults, although these differences were not statistically significant (table 2).

To evaluate potential mechanisms responsible for the greater stability of ventilation in children, their apnoea threshold for $\mathrm{CO}_{2}$ was compared with that of adults (figs 1 and 3). This analysis revealed a lower apnoea threshold in children (table 2). Since the mean $\mathrm{PET}, \mathrm{CO}_{2}$ was similar in children and adults, this suggested a greater $\mathrm{CO}_{2}$ reserve in children during both nights at 3,540 m. Moreover, children had a significantly shorter lung-to-finger circulation time than adults (table 2), and the cycle time in children was also shorter than the corresponding value in adults.

Figure 4 further illustrates factors responsible for the greater stability of ventilation in children compared with adults. The relationship between alveolar ventilation $\left(V^{\prime} \mathrm{A}\right)$ and alveolar $\mathrm{PCO}_{2}\left(P \mathrm{~A}, \mathrm{CO}_{2}\right)$, i.e. the isometabolic line, is defined as [30]:

$$
V^{\prime} \mathrm{A}=\mathrm{K} \times V^{\prime} \mathrm{CO}_{2} / P \mathrm{~A}, \mathrm{CO}_{2}
$$

where $\mathrm{K}$ is the constant and $V^{\prime} \mathrm{CO}_{2}$ is the $\mathrm{CO}_{2}$ production. $V^{\prime} \mathrm{A}$ is expressed in per cent of the value during eupnoea since its absolute value is not known and varies between children and adults. Although $V^{\prime} \mathrm{CO}_{2}$ and the constant $\mathrm{K}$ have different values for children and adults, this has no effect on the metabolic line if $V^{\prime} \mathrm{A}$ is expressed in per cent $V^{\prime} \mathrm{A}$ at eupnoea and $\mathrm{K} \times V^{\prime} \mathrm{CO}_{2}$ remains constant within individuals during stable resting conditions. During the first night at $3,540 \mathrm{~m}$, the eupnoeic $P$ ET, $\mathrm{CO}_{2}$ (the surrogate for $\mathrm{PA}, \mathrm{CO}_{2}$ ) at $100 \% V^{\prime} \mathrm{A}$ was $32 \mathrm{mmHg}$ in both children and adults (table 1). The apnoeic threshold $P$ ET, $\mathrm{CO}_{2}$ was 27 and $30 \mathrm{mmHg}$ in children and adults, respectively (table 2). The lines connecting the eupnoeic $P A, \mathrm{CO}_{2}$ at $100 \% V^{\prime} \mathrm{A}$ on the metabolic line with the apnoeic threshold $P \mathrm{~A}_{1} \mathrm{CO}_{2}$ at $V^{\prime} \mathrm{A}=0$ reflect the ventilatory responsiveness for $\mathrm{PCO}_{2}$ below eupnoea $\left(\Delta V^{\prime} \mathrm{A} / \triangle P \mathrm{~A}, \mathrm{CO}_{2}=100 \% V^{\prime} \mathrm{A}\right.$ eupnoea $/ \mathrm{CO}_{2}$ reserve). The mean value of $\Delta V^{\prime} \mathrm{A} / \triangle P \mathrm{~A}, \mathrm{CO}_{2}$ was 2.5 times greater in adults than in children (50 and $20 \% V^{\prime} \mathrm{A}$ eupnoea per $\mathrm{mmHg} P \mathrm{~A}_{1} \mathrm{CO}_{2}$, respectively; fig. 4). The increase in $V^{\prime} \mathrm{A}$ required to drive $P A, C_{2}$ from the eupnoeic level to the apnoeic threshold is much smaller in adults than in children (7 and 19\%, respectively), which contributes to ventilatory instability in adults.

No symptoms or signs of high-altitude pulmonary oedema, ataxia or impaired consciousness that would have suggested impending high-altitude cerebral oedema in any of the participants (apart from the child excluded because of severe AMS) were found. Nevertheless, $10(50 \%)$ out of the 20 children and six $(30 \%)$ out of the 20 adults $(p=0.1)$ fulfilled the criteria for AMS according to the ESQ criteria (AMS-C $\geqslant 0.7$ ) at least once during their stay at $3,450 \mathrm{~m}$. AMS-C scores of children were not statistically different from the corresponding values in adults (table 3 ). There was no significant correlation for both nights at high altitude between AMS-C scores and $V^{\prime} \mathrm{E}$ (children: $\mathrm{R}=0.24$; adults: $\mathrm{R}=0.03$ ), $\mathrm{O}_{2}$ saturation (children: $\mathrm{R}=0.05$; adults: $\mathrm{R}=0.14$ ), $P \mathrm{ET}, \mathrm{CO}_{2}$ (children: $\mathrm{R}=0.06$; adults: 
TABLE 2 Nocturnal periodic breathing and transient respiratory events

\begin{tabular}{|c|c|c|c|c|c|}
\hline \multicolumn{3}{|c|}{ Children } & \multicolumn{3}{|c|}{ Adults } \\
\hline \multirow[t]{2}{*}{ Baseline $490 \mathrm{~m}$} & \multicolumn{2}{|c|}{$3450 \mathrm{~m}$} & \multirow[t]{2}{*}{ Baseline $490 \mathrm{~m}$} & \multicolumn{2}{|c|}{$3450 \mathrm{~m}$} \\
\hline & Day 1 & Day 2 & & Day 1 & Day 2 \\
\hline 20 & 19 & 17 & 20 & 19 & 19 \\
\hline $5.3 \pm 2.6$ & $34.7 \pm 26.1^{+, \S}$ & $36.0 \pm 31.9^{\S}$ & $2.3 \pm 1.6$ & $56.6 \pm 25.7^{\S}$ & $43.2 \pm 26.9^{\bullet, 5}$ \\
\hline NA & $9 \pm 2$ & $9 \pm 3$ & NA & $8 \pm 2$ & $7 \pm 2$ \\
\hline NA & $81 \pm 4$ & $81 \pm 4$ & NA & $80 \pm 3$ & $82 \pm 4^{\circ}$ \\
\hline $7.1 \pm 2.8$ & $32.5 \pm 24.6^{+, 5}$ & $32.5 \pm 26.8^{\S}$ & $3.5 \pm 2.3$ & $54.1 \pm 26.2^{\S}$ & $39.5 \pm 23.9^{4,5}$ \\
\hline $0 \pm 0$ & $8 \pm 11^{+, \S}$ & $9 \pm 13^{+, 5}$ & $0 \pm 0$ & $34 \pm 24^{\S}$ & $22 \pm 17^{\bullet, 5}$ \\
\hline NA & $17.0 \pm 2.1^{+}$ & $18.5 \pm 4.1^{+}$ & NA & $28.0 \pm 5.1$ & $31.5 \pm 7.7$ \\
\hline $8.5 \pm 1.5^{+}$ & $7.4 \pm 0.8^{+}$ & $7.9 \pm 0.9^{+}$ & $12.0 \pm 1.4$ & $11.6 \pm 3.2$ & $11.9 \pm 2.0$ \\
\hline NA & $9.4 \pm 2.0^{+}$ & $10.5 \pm 4.1^{+}$ & NA & $16.5 \pm 5.5$ & $19.7 \pm 8.1$ \\
\hline NA & $27 \pm 2^{+}$ & $27 \pm 2^{+}$ & NA & $30 \pm 2$ & $30 \pm 2$ \\
\hline NA & $4.6 \pm 3.5^{+}$ & $6.4 \pm 3.1^{+}$ & NA & $1.7 \pm 2.5$ & $1.2 \pm 1.4$ \\
\hline NA & $11.8 \pm 1.2^{+}$ & $11.6 \pm 0.8^{+}$ & NA & $22.2 \pm 4.1$ & $21.6 \pm 1.9$ \\
\hline NA & $8.3 \pm 0.9^{+}$ & $8.1 \pm 0.7^{+}$ & NA & $12.4 \pm 2.2$ & $12.0 \pm 0.9$ \\
\hline $41 \pm 17$ & $54 \pm 23^{+, \S}$ & $42 \pm 26^{+}$ & $24 \pm 13$ & $29 \pm 22$ & $18 \pm 11$ \\
\hline
\end{tabular}

\section{Subjects $\mathbf{n}$}

$\mathrm{O}_{2}$ desaturation index $\geqslant 4 \%$ per $\mathrm{h}$ TIB

Drop in $\mathrm{Sp}, \mathrm{O}_{2}$ during desaturations \%

Minimal $\mathrm{Sp}, \mathrm{O}_{2}$ during desaturations \%

AHI $\cdot h^{-1}$ TIB

Time with periodic breathing \% of TIB

Cycle length $\mathbf{s}$

Apnoea duration $\mathbf{s}$

Hyperpnoea duration s

$\mathrm{CO}_{2}$ apnoea threshold $\mathrm{mmHg}$

$\mathrm{CO}_{2}$ reserve, $\triangle \mathrm{PET}, \mathrm{CO}_{2}{ }^{\#} \mathrm{mmHg}$

Circulation time s

Circulation time s/body height $\mathrm{m}$

Sighs during TIB
Data are presented as mean $\pm \mathrm{SD}$, unless otherwise stated. TIB: time in bed; $\mathrm{Sp}, \mathrm{O}_{2}: \mathrm{O}_{2}$ saturation by pulse oximetry; $\mathrm{AHI}$ : apnoea/hypopnoea index; $\triangle P E \mathrm{ET}, \mathrm{CO}_{2}:$ change in end-tidal $\mathrm{CO}_{2}$ tension; NA: not applicable as no periodic breathing was detected. ${ }^{\#}$ : was calculated as the difference between eupnoeic $P \mathrm{ET}, \mathrm{CO}_{2}$ and the $\mathrm{CO}_{2}$ apnoea threshold. $: p<0.05$ versus day $1 ;^{+}: p<0.05$ versus adults; ${ }^{\varsigma}$ : $p<0.05$ versus $460 \mathrm{~m}$.
$\mathrm{R}=0.13$ ), and per cent time with periodic breathing (children: $\mathrm{R}=0.14$; adults: $\mathrm{R}=0.08 ; \mathrm{p}=$ nonsignificant (NS) for all analyses). Multiple regression analysis revealed no association of $V^{\prime} \mathrm{E}, \mathrm{O}_{2}$ saturation, $P \mathrm{ET}, \mathrm{CO}_{2}$ and per cent time with periodic breathing on the first and second night at $3,450 \mathrm{~m}$ with AMS-C scores in the following morning in children $\left(\mathrm{R}^{2}=0.09, \mathrm{p}=\mathrm{NS}\right)$ or adults $\left(\mathrm{R}^{2}=0.07, \mathrm{p}=\mathrm{NS}\right)$.

To evaluate a potential genetically determined component of ventilatory adaptation to hypoxia, changes in $V^{\prime} \mathrm{E}, \mathrm{O}_{2}$ saturation,

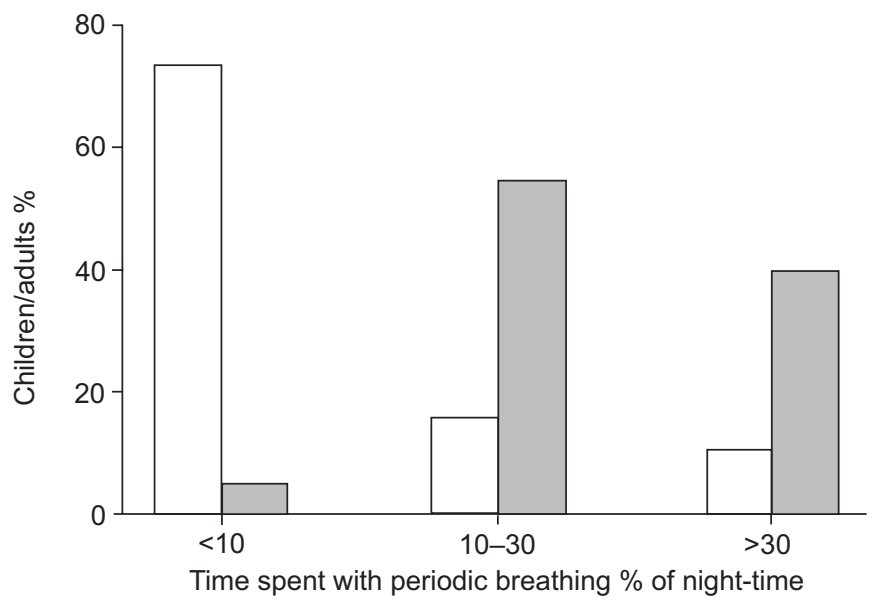

FIGURE 2. The percentage of the night-time spent with periodic breathing was classified into three groups: $<10 \%, 10-30 \%,>30 \%$. Most of the children ( $\square$ ) spent $<10 \%$ of the night-time with periodic breathing. In contrast, almost all adults ( $\square$ ) spent $>10 \%$ of the night-time in periodic breathing.
$P$ ET, $\mathrm{CO}_{2}$ and per cent time in periodic breathing from baseline at $490 \mathrm{~m}$ to the first and second night at 3,450 m were correlated among each of the 19 pairs of children and fathers. Multiple regression analysis did not reveal any statistically significant relationship of physiological variables within families (data not shown).

\section{DISCUSSION}

This is the first study to provide detailed data on nocturnal breathing pattern and ventilation in children acutely exposed to high altitude. Using calibrated respiratory inductive plethysmography and other unobtrusive monitoring techniques during 2 successive nights at 3,450 m, it was found that children had a similar degree of hypoxaemia and a proportional increase in mean ventilation at altitude as their fathers who accompanied them. In contrast, periodic breathing was much less pronounced in children than adults. The greater stability of breathing in children was related to a lower apnoea threshold for $\mathrm{CO}_{2}$, a larger $\mathrm{CO}_{2}$ reserve and a shorter circulation time compared with adults. Half of the children and $30 \%$ of the adults suffered from AMS during their stay at $3,450 \mathrm{~m}$. Therefore, the greater stability of ventilation in children did not translate into a clinically superior tolerance of high altitude.

Acute exposure to hypobaric hypoxia at $3,450 \mathrm{~m}$ resulted in a similar degree of hypoxaemia in children and adults with a mean arterial $\mathrm{O}_{2}$ saturation of $84-86 \%$ (table 1), which is comparable to the mean nocturnal $\mathrm{O}_{2}$ saturation of $86 \%$ previously observed in healthy adults at 3,605 $\mathrm{m}$ [8], but lower than the value of $91 \%$ recorded at 3,109 $\mathrm{m}$ in children aged 3 36 months [31]. According to the expected ventilatory stimulation at altitude [2], $V^{\prime} \mathrm{E}$ and mean inspiratory flow, which 
a)
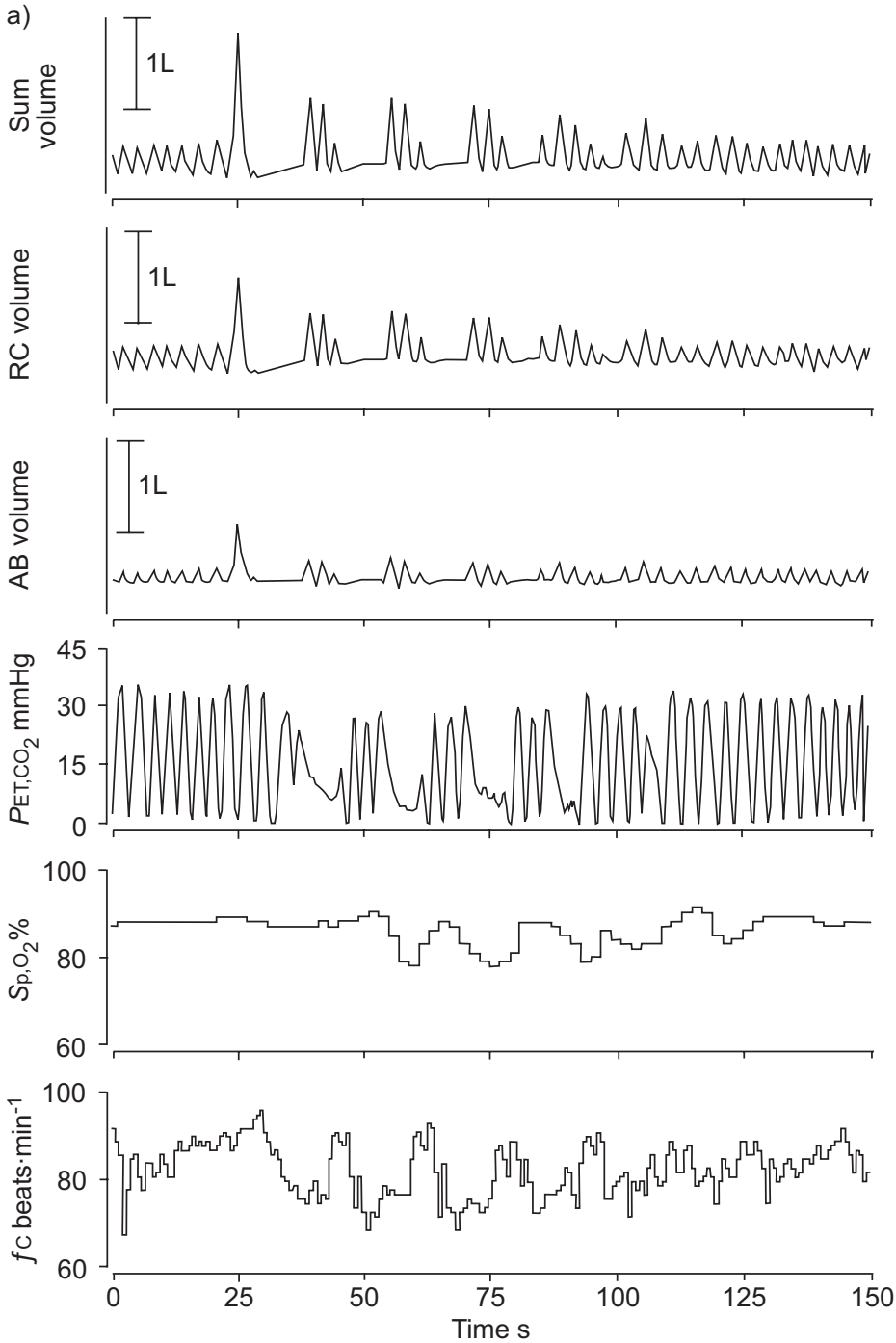
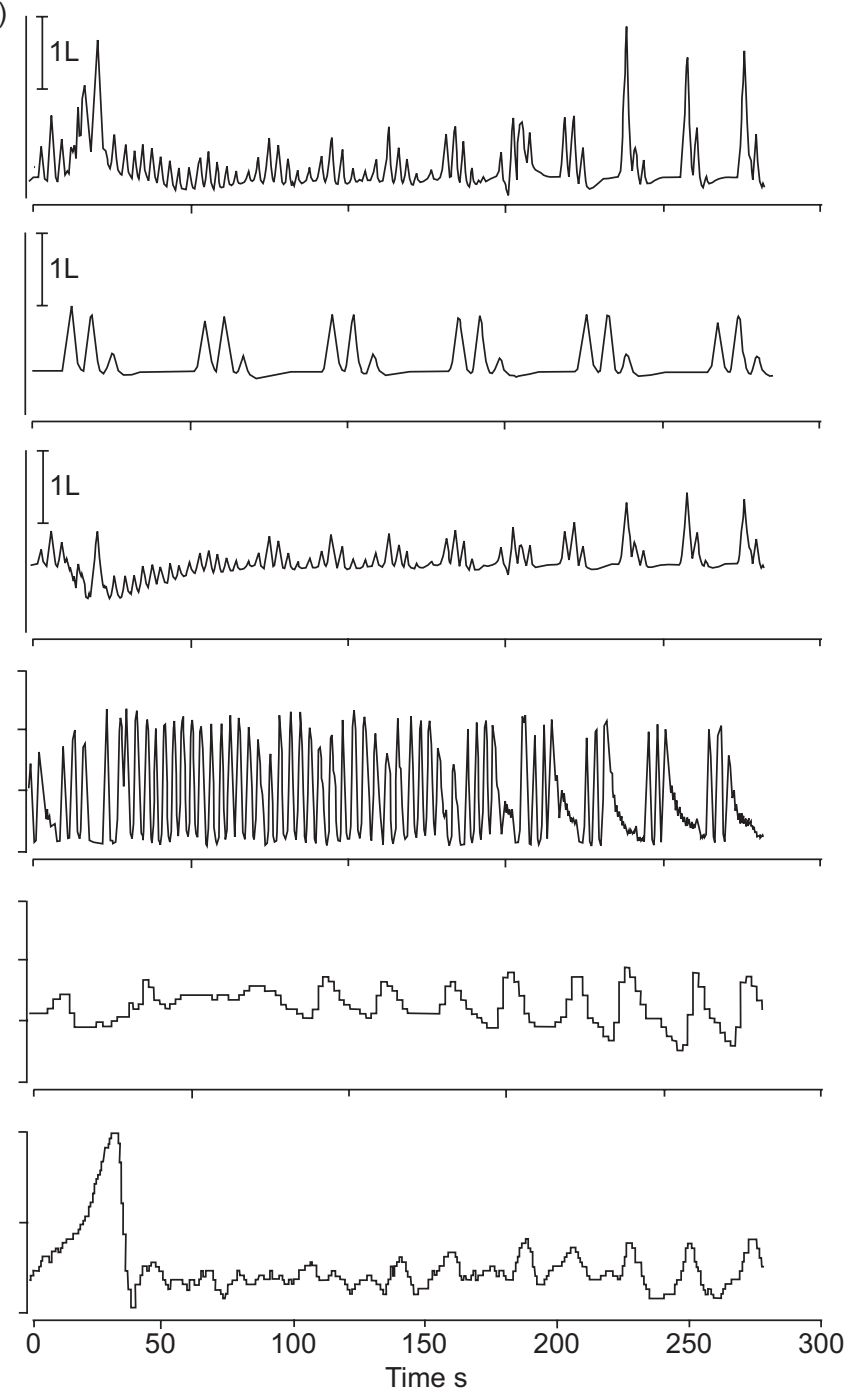

FIGURE 3. Time series of inductive plethysmographic recordings obtained at $3,450 \mathrm{~m}$ reflecting the volume of the ribcage (RC), abdominal volume (AB), and their sum, the lung volume, along with end-tidal carbon dioxide tension $\left(\mathrm{PET}_{\mathrm{C}} \mathrm{CO}_{2}\right)$, arterial oxygen saturation measured by pulse oximetry $\left(\mathrm{Sp}, \mathrm{O}_{2}\right)$ and cardiac frequency $(f \mathrm{C})$. a) $\mathrm{A}$ short sequence of periodic breathing from a child begins with a sigh as the initial disturbance. The breathing pattern normalises after only four cycles of periodic breathing consistent with a stable respiratory control system. b) A recording obtained in an adult reveals irregular, large breaths that trigger periodic breathing with progressively increasing fluctuations in amplitude, suggesting instability of the respiratory control system.

reflect respiratory centre drive [32], were proportionally increased by $22 \%$ to $42 \%$ in children and adults, while $P$ ET, $\mathrm{CO}_{2}$, the study surrogate of $\mathrm{Pa}_{1} \mathrm{CO}_{2}$, was decreased to $33 \mathrm{mmHg}$, indicating a similar degree of hypoxic-induced hyperventilation in children and adults (table 1).

Although altitude exposure resulted in high counts of central apnoeas/hypopnoeas, which occurred as part of a periodic breathing pattern in children and adults, this was significantly less pronounced in children (table 2). The shorter cycle length of periodic breathing additionally contributed to a much lower fraction of the night-time spent with periodic breathing, i.e. $<10 \%$, compared with $22-34 \%$ in adults, which is similar to the corresponding value of $25 \%$ previously observed in adults at 3,650 m [8]. To evaluate potential mechanisms responsible for the greater stability of ventilation in children, the current authors applied the concepts described by DEMPSEY [30],
NAKAYAMA et al. [14] and XIE et al. [33], as illustrated in figure 4 . The present authors measured the apnoea threshold for $\mathrm{CO}_{2}$ and found it to be $3 \mathrm{mmHg}$ lower in children than adults, i.e. 27 versus $30 \mathrm{mmHg}$ in both nights at $3,450 \mathrm{~m}$ (table 2, figs 1 and 4). As the mean nocturnal $P \mathrm{ET}, \mathrm{CO}_{2}$ was not significantly different between children and adults, this indicated that the $\mathrm{CO}_{2}$ reserve, i.e. the difference between baseline $\mathrm{PCO}_{2}$ and the apnoea threshold, was more reduced in adults. This explains their greater susceptibility to ventilatory instability. These findings principally agree with those of XIE and co-workers $[29,33]$ who observed a reduced $\mathrm{CO}_{2}$ reserve during hypoxia compared with normoxia in healthy adults hyperventilated by pressure support ventilation until central apnoea occurred. Although the present estimation of the apnoea threshold and the $\mathrm{CO}_{2}$ reserve cannot be directly compared with previous studies that used face masks, mechanical ventilation and sedation [29, 33], the current 


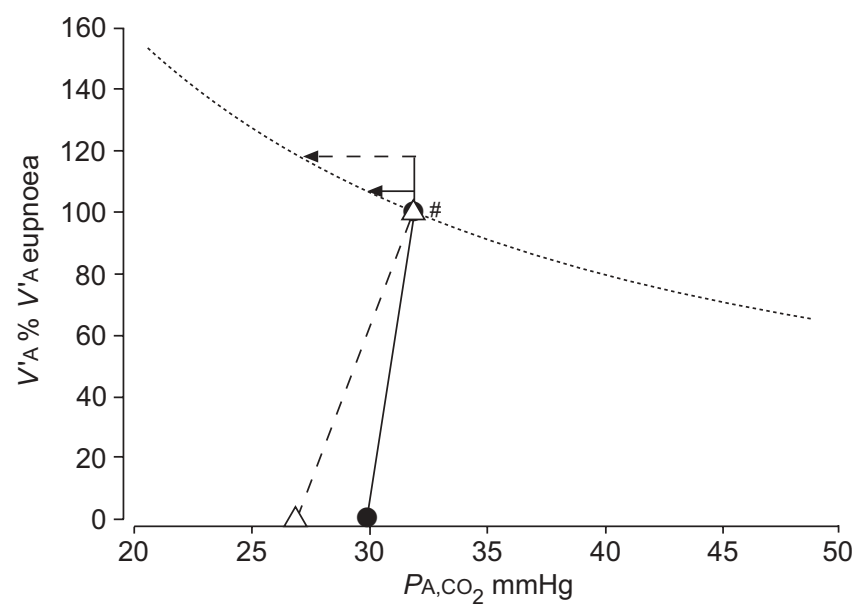

FIGURE 4. Diagrammatic representation of the relationship between alveolar ventilation $\left(V^{\prime} \mathrm{A}\right)$ and alveolar $\mathrm{CO}_{2}$ tension $\left(P \mathrm{~A}, \mathrm{CO}_{2}\right)$ showing the factors responsible for the greater ventilatory stability in children compared with adults. The line connecting the eupnoeic $P A, C O_{2}$ in children with the apnoeic threshold $(\triangle:----)$ is less sleep than in adults (- : - - - ), and the increase in $V^{\prime} A$ required to drive $P A, C O_{2}$ below the apnoeic threshold (arrows) is greater in children (19\%) than in adults (7\%). The apnoeic threshold is marked at $V^{\prime} \mathrm{A}=0$. " : eupnoeic level of $P \mathrm{~A}_{1}, \mathrm{CO}_{2}$.

authors believe that the present results, obtained in a more natural setting with unobtrusive techniques, reflect relevant physiological mechanisms. In adults, periodic breathing was further promoted by an only modestly increased heart rate at altitude associated with a long circulation time (table 2), which additionally impaired a stable control of ventilation [11] and contributed to the longer hyperpnoea duration and cycle time of periodic breathing compared with children. These findings are similar to the differences among patients with central sleep apnoea associated with heart failure compared to those with normal cardiac function [34]. Thus, a higher heart and breath rate and a shorter circulation time, even when corrected for height (table 2), allows children a more dynamic cardiorespiratory adaptation to high altitude compared with adults, and in combination with a greater $\mathrm{CO}_{2}$ reserve, reduces their propensity to periodic breathing. These concepts are consistent with a greater response of heart and breath rate and ventilation during a hypoxic challenge, as well as with a lower apnoea threshold for $\mathrm{CO}_{2}$ in children compared with adults, as reported by MARCUS et al. [15].

Children tended to have more pronounced swings in $\mathrm{O}_{2}$ saturation during periodic breathing than adults ( 9 versus 7 $8 \%$, table 2), although these differences were not statistically significant. As the minimal $\mathrm{O}_{2}$ saturation was $80-82 \%$ (table 2) and the mean saturation $84-85 \%$ (table 1 ), this indicated that the $\mathrm{O}_{2}$ saturation oscillated around the mean value, dropping from baseline during desaturations and overshooting during resaturations (figs 1 and 3). Hypoxic ventilatory stimulation during rapid and pronounced drops in $\mathrm{O}_{2}$ saturation in children might have contributed to their shorter apnoea duration (table 2). Since adults did not desaturate more than children despite longer apnoeas they might have had larger $\mathrm{O}_{2}$ stores in relation to $\mathrm{O}_{2}$ consumption.

Actigraphic recordings suggested similar total sleep duration for children and adults. However, the current authors could
TABLE 3 Symptoms of acute mountain sickness (AMS)

\begin{tabular}{|c|c|c|c|c|}
\hline \multirow{2}{*}{$\begin{array}{l}\text { AMS-C scores at } \\
3,450 \mathrm{~m}\end{array}$} & \multicolumn{2}{|c|}{ Children } & \multicolumn{2}{|c|}{ Adults } \\
\hline & Mean $\pm S D$ & $\begin{array}{c}\text { Subjects }^{\#} \\
\mathbf{n}\end{array}$ & Mean $\pm S D$ & $\begin{array}{c}\text { Subjects } \\
\mathbf{n}\end{array}$ \\
\hline Day 1 evening & $0.49 \pm 0.77$ & 5 & $0.45 \pm 0.59$ & 4 \\
\hline Day 2 morning & $0.46 \pm 0.57$ & 6 & $0.30 \pm 0.34$ & 3 \\
\hline Day 2 evening & $0.23 \pm 0.34$ & 2 & $0.06 \pm 0.08$ & 0 \\
\hline Day 3 morning ${ }^{+}$ & $0.10 \pm 0.17$ & 0 & $0.12 \pm 0.18$ & 0 \\
\hline
\end{tabular}

not assess potential differences in sleep-wakefulness transitions and sleep-stage distribution that might have also influenced the breathing pattern at high altitude. Previous studies have shown that periodic breathing in hypoxia occurred less frequently in rapid eye movement compared with nonrapid eye movement sleep [5, 35], and children are known to spend a higher proportion of their total sleep time in rapid eye movement sleep. Differences in the ventilatory response to hypoxia and hypercapnia in children and adults may have further influenced the prevalence of periodic breathing [15].

Children sighed significantly more frequently during the night than adults, and their number of sighs increased with ascent from low to high altitude (table 2). Although sighs have been described during sleep in infants [36] and in adults [28], their physiological significance is not well understood. Some data in infants suggest a role of sighs in restoration of lung mechanics [37] and in resetting the neuro-respiratory control system [36] or as a trigger of arousals during sleep [38]. Sighs in prepubertal children have not been investigated in detail. As an increase in sigh frequency at altitude was found in children but not in adults (table 2), sighs may represent a specific response of children to hypobaric hypoxia. Although the transient hypocapnia and neuromechanical inhibition (lung stretch reflex) [39] following sighs may trigger central apnoea, the prevalence of periodic breathing in children was significantly lower than in adults despite their higher number of sighs. This further corroborates the greater stability of their respiratory control system (fig. 2).

Half of the children and $30 \%$ of adults experienced significant symptoms of AMS (defined by $\geqslant 0.7$ points in the ESQ cerebral score) during their stay at 3,450 $\mathrm{m}$ (table 3). For comparisons, all six children aged 6 months to 4 yrs and five out of 10 children aged 13-18 yrs had significant symptoms of AMS (defined by $\geqslant 3$ points in the Lake Louise questionnaire) after one night at 3,500 $\mathrm{m}$ (very young children were evaluated with a modified questionnaire) [16]. Since no statistical correlation was found among AMS scores and measures of periodic breathing in the current study, an interaction between periodic breathing and severity of AMS symptoms seems unlikely or 
weak. This is in agreement with the current authors' previous observations in adults ascending to Capanna Regina Margherita $(4,559 \mathrm{~m})$ [8].

The present authors did not identify any significant correlation among corresponding breathing pattern characteristics in children and their fathers, but as the study may not have been appropriately powered and did not include mothers, it might have failed to detect potential genetically determined properties of ventilatory control.

In summary, the present analysis of nocturnal breathing patterns in children and adults during acute high-altitude exposure revealed a similar degree of hypoxaemia and hyperventilation but significantly less periodic breathing in children compared with adults. This suggests a more stable control of ventilation in children than in adults at high altitude, which is related to their lower apnoea threshold for $\mathrm{CO}_{2}$, a larger $\mathrm{CO}_{2}$ reserve and a shorter circulation time.

\section{REFERENCES}

1 Pollard AJ, Niermeyer S, Barry P, et al. Children at high altitude: an international consensus statement by an ad hoc committee of the International Society for Mountain Medicine, March 12, 2001. High Alt Med Biol 2001; 2: 389-403.

2 White DP, Gleeson K, Pickett CK, Rannels AM, Cymerman A, Weil JV. Altitude acclimatization: influence on periodic breathing and chemoresponsiveness during sleep. J Appl Physiol 1987; 63: 401-412.

3 Burgess KR, Johnson PL, Edwards N. Central and obstructive sleep apnoea during ascent to high altitude. Respirology 2004; 9: 222-229.

4 Berssenbrugge AD, Dempsey JA, Skatrud JB. Effects of sleep state on ventilatory acclimatization to hypoxia in humans. J Appl Physiol 1984; 57: 1089-1096.

5 Berssenbrugge A, Dempsey J, Iber C, Skatrud J, Wilson P. Mechanisms of hypoxia-induced periodic breathing during sleep in humans. J Physiol 1983; 343: 507-526.

6 Anholm JD, Powles AC, Downey R III, et al. Operation Everest II: arterial oxygen saturation and sleep at extreme simulated altitude. Am Rev Respir Dis 1992; 145: 817-826.

7 Khoo MC, Anholm JD, Ko SW, et al. Dynamics of periodic breathing and arousal during sleep at extreme altitude. Respir Physiol 1996; 103: 33-43.

8 Erba P, Anastasi S, Senn O, Maggiorini M, Bloch KE. Acute mountain sickness is related to nocturnal hypoxemia but not to hypoventilation. Eur Respir J 2004; 24: 303-308.

9 Eichenberger U, Weiss E, Riemann D, Oelz O, Bartsch P. Nocturnal periodic breathing and the development of acute high altitude illness. Am J Respir Crit Care Med 1996; 154: 1748-1754.

10 Lahiri S, Maret K, Sherpa MG. Dependence of high altitude sleep apnea on ventilatory sensitivity to hypoxia. Respir Physiol 1983; 52: 281-301.

11 Khoo MC, Kronauer RE, Strohl KP, Slutsky AS. Factors inducing periodic breathing in humans: a general model. $J$ Appl Physiol 1982; 53: 644-659.

12 Guyton AC, Rowell JW, Moore JW. Basic oscillating mechanism of Cheyne-Stokes breathing. Am J Physiol 1956; 187: 395-398.
13 Cherniack NS, von Euler C, Homma I, Kao FF. Experimentally induced Cheyne-Stokes breathing. Respir Physiol 1979; 37: 185-200.

14 Nakayama H, Smith CA, Rodman JR, Skatrud JB, Dempsey JA. Effect of ventilatory drive on carbon dioxide sensitivity below eupnea during sleep. Am J Respir Crit Care Med 2002; 165: 1251-1260.

15 Marcus CL, Glomb WB, Basinski DJ, Davidson SL, Keens TG. Developmental pattern of hypercapnic and hypoxic ventilatory responses from childhood to adulthood. J Appl Physiol 1994; 76: 314-320.

16 Moraga FA, Osorio JD, Vargas ME. Acute mountain sickness in tourists with children at Lake Chungará $(4400 \mathrm{~m})$ in northern Chile. Wilderness Environ Med 2002; 13: 31-35.

17 Lahiri S, Data P. Chemosensitivity and regulation of ventilation during sleep at high altitudes. Int J Sports Med 1992; 13: Suppl. 4, S31-S33.

18 Kriemler S, Kohler M, Zehnder M, Bloch KE, Brunner-La Rocca H. Successful treatment of severe acute mountain sickness and excessive pulmonary hypertension with dexamethasone in a prepubertal girl. High Alt Med Biol 2006; 7: 256-261.

19 Marshall WA, Tanner JM. Variations in pattern of pubertal changes in girls. Arch Dis Child 1969; 44: 291-303.

20 Marshall WA, Tanner JM. Variations in the pattern of pubertal changes in boys. Arch Dis Child 1970; 45: 13-23.

21 Sampson JB, Cymerman A, Burse RL, Maher JT, Rock PB. Procedures for the measurement of acute mountain sickness. Aviat Space Environ Med 1983; 54: 1063-1073.

22 Sackner MA, Watson H, Belsito AS, et al. Calibration of respiratory inductive plethysmograph during natural breathing. J Appl Physiol 1989; 66: 410-420.

23 Bloch KE, Li Y, Sackner MA, Russi EW. Breathing pattern during sleep disruptive snoring. Eur Respir J 1997; 10: 576-586.

24 Cole RJ, Kripke DF, Gruen W, Mullaney DJ, Gillin C. Automatic sleep/wake identification from wrist actigraphy. Sleep 1992; 15: 461-469.

25 Waggener TB, Brusil PJ, Kronauer RE, Gabel RA, Inbar GF. Strength and cycle time of high-altitude ventilatory patterns in unacclimatized humans. J Appl Physiol 1984; 56: 576-581.

26 Sleep-related breathing disorders in adults, recommendations for syndrome definition and measurement techniques in clinical research. The report of an American Academy of Sleep Medicine Task Force. Sleep 1999; 22: 667-689.

27 Tang JP, Rosen CL, Larkin EK, et al. Identification of sleepdisordered breathing in children: variation with event definition. Sleep 2002; 25: 72-79.

28 Perez-Padilla R, West P, Kryger MH. Sighs during sleep in adult humans. Sleep 1983; 6: 234-243.

29 Xie A, Skatrud JB, Puleo DS, Dempsey JA. Influence of arterial $\mathrm{O}_{2}$ on the susceptibility to posthyperventilation apnea during sleep. J Appl Physiol 2006; 100: 171-177.

30 Dempsey JA. Crossing the apnoeic threshold: causes and consequences. Exp Physiol 2005; 90: 13-24.

31 Yaron $\mathrm{M}$, Niermeyer $\mathrm{S}$, Lindgren $\mathrm{KN}$, Honigman $\mathrm{B}$, Strain JD, Cairns CB. Physiologic response to moderate 
altitude exposure among infants and young children. High Alt Med Biol 2003; 4: 53-59.

32 Tobin MJ, Mador MJ, Guenther SM, Lodato RF, Sackner MA. Variability of resting respiratory drive and timing in healthy subjects. J Appl Physiol 1988; 65: 309-317.

33 Xie A, Skatrud JB, Dempsey JA. Effect of hypoxia on the hypopnoeic and apnoeic threshold for $\mathrm{CO}_{2}$ in sleeping humans. J Physiol 2001; 535: 269-278.

34 Hall MJ, Xie A, Rutherford R, Ando S, Floras JS, Bradley TD. Cycle length of periodic breathing in patients with and without heart failure. Am J Respir Crit Care Med 1996; 154: 376-381.

35 Beaumont M, Goldenberg F, Lejeune D, Marotte H, Harf A, Lofaso F. Effect of zolpidem on sleep and ventilatory patterns at simulated altitude of 4,000 meters. Am J Respir Crit Care Med 1996; 153: 1864-1869.

36 Baldwin DN, Suki B, Pillow JJ, Roiha HL, Minocchieri S, Frey U. Effect of sighs on breathing memory and dynamics in healthy infants. J Appl Physiol 2004; 97: 1830-1839.

37 Davis GM, Moscato J. Changes in lung mechanics following sighs in premature newborns without lung disease. Pediatr Pulmonol 1994; 17: 26-30.

38 McNamara F, Lijowska AS, Thach BT. Spontaneous arousal activity in infants during NREM and REM sleep. J Physiol 2002; 538: 263-269.

39 Leevers AM, Simon PM, Dempsey JA. Apnea after normocapnic mechanical ventilation during NREM sleep. J Appl Physiol 1994; 77: 2079-2085. 